
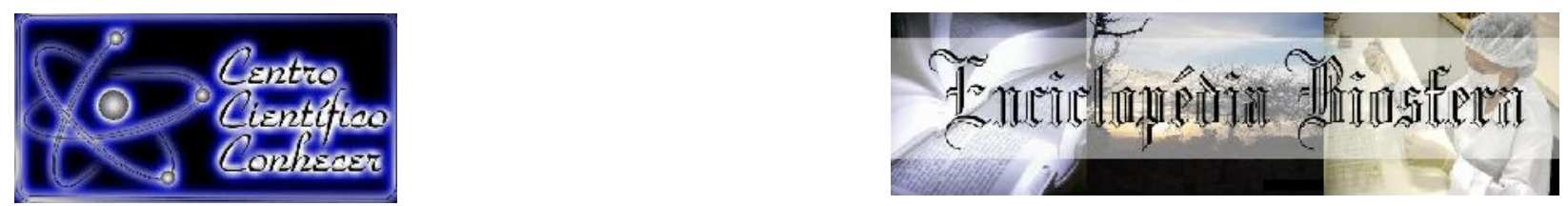

\title{
ESTUDO RETROSPECTIVO DO MASTOCITOMA CUTÂNEO CANINO E PAPEL DO AZUL DE TOLUIDINA NA GRADUAÇÃO HISTOLÓGICA DE MASTOCITOMAS
}

\footnotetext{
Alessandra Aparecida Medeiros-Ronchi ${ }^{1}$, Gleysi Fernanda Guerra de Souza ${ }^{2}$, Lígia Assunção Oliveira ${ }^{3}$, Lígia Fernandes Gundim ${ }^{4}$

${ }^{1}$ Professora Doutora do Curso de Veterinária da Universidade Federal de Uberlândia (UFU)

${ }^{2}$ Graduanda em Medicina Veterinária pela Universidade Federal de Uberlândia (UFU)

${ }^{3}$ Residente em Patologia Animal, Universidade Federal de Uberlândia (UFU)

${ }^{4}$ Doutoranda em Ciências Veterinárias pela Universidade Federal de Uberlândia (UFU) (ligia_fg@hotmail.com)
}

Recebido em: 22/09/2018 - Aprovado em: 23/11/2018 - Publicado em: 03/12/2018 DOI: 10.18677/EnciBio_2018B47

\begin{abstract}
RESUMO
O mastocitoma é uma das neoplasias de pele mais comuns em cães. A partir da análise histológica destes tumores, obtêm-se a graduação histológica, porém há grande divergência entre os patologistas na classificação de grau II. Objetivou-se verificar se a coloração de azul de toluidina (AT) auxilia a classificação de mastocitomas grau II e realizar estudo epidemiológico e clínicopatológico de mastocitomas cutâneos caninos atendidos no Hospital Veterinário da Universidade Federal de Uberlândia. Foram analisados 85 cães, sendo $71 \%$ fêmeas e $29 \%$ machos. Os cães mestiços foram mais frequentemente afetados (44\%) e as faixas etárias entre 6 a 10 anos e 11-15 anos foram as mais frequentes $(p, 0,05)$. Analisando a relação entre idade e graduação, notou-se que animais acima de 6 anos apresentaram mais tumores Grau I. Macroscopicamente, os tumores eram predominantemente nodulares $(71,8 \%)$, brancacentos $(45,9 \%), 30,6$ eram aderidos, $51,8 \%$ não eram ulcerados e $50,6 \%$ mediam menos que $5 \mathrm{~cm}$. As localizações mais frequentes foram o tronco (34,1\%) e a região inguinal $(17,6 \%)$. Na graduação histológica, quando classificados em três graus, a maioria das neoplasias foram classificadas como grau II e quando classificadas em dois graus, 65,9\% foram graduados como de baixo grau e 31,8\% como alto grau. Dos 40 tumores classificados como grau II, $27,5 \%$ foram reclassificados como grau I na coloração especial de AT e 10\% como grau III. Conclui-se que a graduação histológica influencia no aspecto macroscópico dos mastocitomas e na ulceração. A coloração de azul de toluidina pode ser utilizada na otimização da avaliação de mastocitomas grau II.
\end{abstract}

PALAVRAS-CHAVE: cão, coloração especial.Mastócitos, neoplasia.

\section{RETROSPECTIVE STUDY OF CANINE SKIN MASTOCYTOMA AND PAPER OF TOLUIDINE BLUE IN THE HISTOLOGICAL GRADUATION OF MASTOCITOMAS}

\begin{abstract}
Mast cell tumors is one of the most common dogs skin cancers. Histological analysis of these tumors enable the histological graduation, but there is great divergence among the pathologists in the classification of grade II. The aim of this study was to verify whether toluidine blue staining helps to classify grade II mast cell tumors and to ENCICLOPÉDIA BIOSFERA, Centro Científico Conhecer - Goiânia, v.15 n.28; p.544 2018
\end{abstract}


carry out an epidemiological and clinical-pathological study of canine cutaneous mast cell tumors treated at the Veterinary Hospital of the Federal University of Uberlândia. A total of 85 dogs were analyzed, being $71 \%$ female and $29 \%$ male. The mongrel dogs were more frequently affected (44\%) and the age groups between 6 and 10 years and 11-15 years were the most frequent ( $p, 0.05)$. Analyzing the relationship between age and graduation, animals older than 6 years old showed more Grade I tumors. Macroscopically, the tumors were predominantly nodular $(71.8 \%)$, white (45.9\%), 30.6 were adhered , 51.8\% were not ulcerated and $50.6 \%$ were less than 5 $\mathrm{cm}$. The most frequent sites were the trunk (34.1\%) and the inguinal region (17.6\%). In the histological grading, when classified in three degrees, most of the neoplasms were classified as grade II and when classified in two grades, 65.9\% were graded as low grade and $31.8 \%$ as high grade. Of the 40 tumors classified as grade $11,27.5 \%$ were reclassified as grade I in the special staining of TA and $10 \%$ as grade III. It is concluded that the histological graduation influences the macroscopic mast cell tumors aspect and the ulceration. The toluidine blue staining can be used to optimize the evaluation of grade II mast cell tumors.

KEYWORDS: mast cells, neoplasia, dog, special staining

\section{INTRODUÇÃO}

As neoplasias são consideradas a principal causa de morte na espécie canina (INOUE et al., 2015). Dentre as principais neoplasias que ocorrem nos animais domésticos, destacam-se as neoplasias de pele e dentre essas, o mastocitoma. $\mathrm{Na}$ região de Uberlândia, o mastocitoma e o carcinoma de células escamosas são as neoplasias de pele mais frequentes (COSTA et al., 2017).

Denomina-se mastocitoma a proliferação anormal de mastócitos, sendo a forma cutânea a mais comum, podendo ocorrer envolvimento visceral. Na pele o mastocitoma pode se apresentar macroscopicamente de várias formas e necrose e ulceração são frequentes. Devido à presença de heparina e histamina nos grânulos dos mastócitos, alguns animais podem desenvolver síndrome paraneoplásica, em especial ulceração duodenal (CONCEIÇÃO ; LOURES, 2017).

O diagnóstico definitivo é obtido através da avaliação histológica do tumor, onde os mastócitos podem ser reconhecidos devido à presença de grânulos no citoplasma. A quantidade de grânulos está associada à malignidade: tumores com menos grânulos são indiferenciados e, portanto, mais malignos (PATNAIK et al. 1984). A coloração histoquímica de Azul de Toluidina é utilizada para evidenciar os grânulos, corando-os em magenta (MAGALHÃES et al. 2001).

Quanto à graduação histológica, duas classificações são usadas. A primeira proposta por Patnaik et al. (1984) sugere a graduação em 3 graus, sendo que nas neoplasias de grau I as células são bem diferenciadas, no grau III indiferenciadas, e os tumores intermediários são classificados em grau II. A maioria dos mastocitomas são classificados em grau II, porém a sobrevida e a ocorrência de metástases em cães com mastocitoma grau II é variável, sendo difícil precisar o prognóstico em cães com este tipo de mastocitoma. Além disto há discrepância entre patologistas na avaliação de mastocitomas grau II. Kiupel et al. (2011) propuseram então uma nova classificação, agrupando as neoplasias em baixo e alto grau de malignidade na tentativa de reduzir o número de diagnósticos discrepantes e tornar a variável grau histológico um melhor fator de prognóstico.

O presente estudo objetivou verificar se a coloração de azul de toluidina otimiza a classificação de mastocitomas grau II. Objetivou-se ainda realizar estudo 
epidemiológico e clínicopatológico de casos de mastocitoma cutâneo canino atendidos no Hospital Veterinário da Universidade Federal de Uberlândia (HV-UFU).

\section{MATERIAL E MÉTODOS}

Foram selecionados casos de cães com mastocitoma cutâneo atendidos no Hospital Veterinário da Universidade Federal de Uberlândia (HV-UFU), no período de 2006 a 2016 e submetidos à exérese cirúrgica do tumor. A coleta de dados epidemiológicos como raça, sexo e idade, bem como as características clínicas e a localização do tumor foram realizadas a partir da análise das fichas clínicas de cada cão.

Os cães foram agrupados de acordo com a idade, segundo Bracarense et al. (2012), em animais de 1 a 5 anos, 6 a 10 anos, 11 a 15 anos e acima de 15 anos. Os mastocitomas foram agrupados de acordo com a localização segundo Furlani et al. (2008) adaptado em cabeça, tronco, membros e região inguinal. Já quanto ao tamanho do tumor os mastocitomas foram agrupados de acordo com Owen (1980) em T1 (menor de $3 \mathrm{~cm}$ ), T2 (3 a $5 \mathrm{~cm}$ ) e T3 (maior que $5 \mathrm{~cm}$ ).

Após a exérese cirúrgica, fragmentos do tumor foram fixados em formol $10 \%$ tamponado e incluídos em parafina. As amostras foram processadas rotineiramente para confecção de lâminas histológicas coradas com hematoxilina-eosina (HE) e avaliadas através de microscopia de luz. As lâminas foram avaliadas por dois patologistas individualmente, em estudo duplo cego, em microscópio óptico

Avaliou-se os seguintes parâmetros: extensão do tecido envolvida pela neoplasia, celularidade e morfologia celular, índice mitótico e reação estromal. Os casos foram analisados e agrupados de acordo com a graduação histológica segundo Patnaik et al. (1984) em grau I, II e III e de acordo com Kiupel et al. (2011) em mastocitomas de alto e baixo grau.

Os casos de mastocitoma classificados como grau II na classificação de Patnaik et al. (1984) foram selecionados para realização do método histoquímico de azul de toluidina (AT) conforme Culling et al. (1976). Após coradas as lâminas foram novamente analisadas e os mastocitomas reclassificados segundo Patnaik et al. (1984). Os resultados da classificação utilizando a coloração especial foram comparados com os resultados da classificação utilizando as lâminas coradas com HE.

O Teste de Comparação Múltipla entre Proporções foi utilizado no cálculo dos dados epidemiológicos de sexo, idade e raça dos animais analisados ,considerando significância quando $p \geq 0,05$.

\section{RESULTADOS E DISCUSSÃO}

Durante o período estudado foram selecionados 85 cães com mastocitoma cutâneo, de diversas raças e com idade variando entre 3 a 15 anos. Fernandes et al. (2015) relatou que na região de Uberlândia o mastocitoma é o segundo tumor mais frequente $(15,30 \%)$. Já na região de Fortaleza o mastocitoma é relatado como o terceiro tumor cutâneo mais frequente $(11,69 \%)$ (BASTOS et al., 2017).

Destes animais, $71 \%$ eram fêmeas (60/85) e 29\% (25/85) machos (Tabela 1), sendo a frequência de mastocitomas maior em fêmeas $(p<0,05)$. Resultado semelhante foi relatado por Silva et al. (2014) que verificaram as fêmeas como mais acometidas (56\%). No entanto, Braz et al.(2017) descrevem que 53,84\% dos animais com mastocitoma eram machos. Na casuística do HV-UFU o número de fêmeas é superior ao número de machos e pode ter influenciado na maior frequência de mastocitomas em fêmeas. 
TABELA 1- Características clinicopatológicas de cães com mastocitoma atendidos no Hospital Veterinário da Universidade Federal de Uberlândia.

\begin{tabular}{|c|c|}
\hline \multicolumn{2}{|l|}{$\begin{array}{l}\text { Número de pacientes } \\
\text { Sexo }\end{array}$} \\
\hline $\begin{array}{ll}\text { Sexo } & \\
& \text { Fêmeas } \\
\text { Machos }\end{array}$ & $\begin{array}{l}60(71 \%)^{\mathrm{a}} \\
25(29 \%)^{\mathrm{b}}\end{array}$ \\
\hline \multicolumn{2}{|l|}{ Idade } \\
\hline $\begin{array}{l}\mathrm{NI} \\
0-5 \\
6-10 \\
11-15\end{array}$ & $\begin{array}{l}11(13 \%)^{\mathrm{a}} \\
10(12 \%)^{\mathrm{a}} \\
35(41 \%)^{\mathrm{b}} \\
29(34 \%)^{\mathrm{b}}\end{array}$ \\
\hline \multicolumn{2}{|l|}{ Raça } \\
\hline $\begin{array}{l}\text { NI } \\
\text { SRD } \\
\text { Labrador } \\
\text { Pitbull } \\
\text { Poodle } \\
\text { Boxer } \\
\text { Pinscher } \\
\text { Rottweiller } \\
\text { Cocker } \\
\text { Daschund } \\
\text { Fox Paulistinha } \\
\text { Basset } \\
\text { Beagle } \\
\text { Golden Retriever } \\
\text { Lhasa Apso } \\
\text { Sharpei } \\
\text { Teckel } \\
\text { Yorkshire }\end{array}$ & $\begin{array}{l}4(5 \%)^{\mathrm{a}} \\
36(44 \%)^{\mathrm{b}} \\
9(11 \%)^{\mathrm{a}} \\
8(9 \%)^{\mathrm{a}} \\
5(6 \%)^{\mathrm{a}} \\
4(5 \%)^{\mathrm{a}} \\
3(4 \%)^{\mathrm{a}} \\
3(4 \%)^{\mathrm{a}} \\
2(2 \%)^{\mathrm{a}} \\
2(2 \%)^{\mathrm{a}} \\
2(2 \%)^{\mathrm{a}} \\
1(1 \%)^{\mathrm{a}} \\
1(1 \%)^{\mathrm{a}} \\
1(1 \%)^{\mathrm{a}} \\
1(1 \%)^{\mathrm{a}} \\
1(1 \%)^{\mathrm{a}} \\
1(1 \%)^{\mathrm{a}} \\
1(1 \%)^{\mathrm{a}}\end{array}$ \\
\hline \multicolumn{2}{|l|}{ Localização } \\
\hline $\begin{array}{l}\text { NI } \\
\text { Múltiplas } \\
\text { Tronco } \\
\text { Inguinal } \\
\text { Membros } \\
\text { Cabeça }\end{array}$ & $\begin{array}{l}8(8,2 \%) \\
14(16,5 \%) \\
29(34,1 \%) \\
15(17,6 \%) \\
10(11,8 \%) \\
9(10,6 \%)\end{array}$ \\
\hline \multicolumn{2}{|l|}{ Número de nódulos } \\
\hline $\begin{array}{l}1 \\
2 \\
>2\end{array}$ & $\begin{array}{l}62(72,9 \%) \\
12(14,1 \%) \\
11(12,9 \%)\end{array}$ \\
\hline \multicolumn{2}{|l|}{ Grau histológico HE } \\
\hline $\begin{array}{r}\text { Patnaik } \\
\text { I } \\
\text { II } \\
\text { III }\end{array}$ & $\begin{array}{l}21(24,7 \%) \\
47(55,3 \%) \\
17(16,5 \%)\end{array}$ \\
\hline $\begin{array}{c}\text { Kiupel } \\
\text { Baixo } \\
\text { Alto }\end{array}$ & $\begin{array}{l}56(65,9 \%) \\
29(31,8 \%)\end{array}$ \\
\hline
\end{tabular}

Letras diferentes entre linhas indicam diferença significativa no teste de comparação entre proporções $(p \leq 0,05)$. 
Cães mestiços (SRD) foram mais acometidos $(44 \%)(p<0,05)$ seguidos por cães da raça Labrador (11\%) e Pitbull (9\%) (Quadro 1). Silva et al. (2014) e Braz et al. (2017) também relataram maior frequência de cães mestiços com mastocitoma. Por outro lado, Shoop et al. (2015) afirmam que animais das raças Boxer, Pug e Staffordshire Bull Terrier têm maior probabilidade de diagnóstico de mastocitoma comparado aos animais mestiços. Assim como ocorreu com o sexo, a alta frequência de cães SRD com mastocitoma pode ser explicada devido à casuística de atendimento do HV - UFU. As faixas etárias entre 6 a 10 anos e 11-15 anos foram as mais frequentemente acometidas $(p, 0,05)$. Já De Carvalho et al. (2017) relataram que animais com idade ente 7 e 12 anos eram mais acometidos.

Analisou-se a relação entre a idade dos animais acometidos por mastocitomas e a graduação dos tumores e foi possível observar que animais acima de 6 anos apresentaram maior número de tumores Grau III (Quadro 2). De Carvalho et al. (2017) relatam que a classificação histológica é dependente da idade, sendo que os cães idosos têm 8 vezes mais chances de terem tumores classificados em alto grau.

Quanto ao aspecto macroscópico, a maioria dos tumores possuía aspecto nodular (61/85 - 71,8\%), 13 em placa $(15,3 \%)$ e em menor número aspecto serpiginoso (3/85 - 3,5\%). Em oito casos $(9,4 \%)$ não havia informações sobre o aspecto do tumor. A maioria dos tumores era brancacenta (39/85 - 45,9\%), 5,85\% avermelhados (5/85) e 7\% apresentava coloração rósea, amarelada ou acinzentada (6/85). Em 35 casos $(41,2 \%)$ não havia informações sobre a coloração do tumor.

Em relação à aderência, 30,6\% (26/85) dos tumores eram aderidos, $29,4 \%$ $(25 / 85)$ não aderidos e 10,6\% (9/85) dos cães apresentaram mais de um nódulo tumoral com aderência ou não. Em vinte e cinco casos $(29,4 \%)$ não havia informações sobre aderência do tumor. Kiupel (2016) afirma que mastocitomas cutâneos têm uma aparência macroscópica altamente variável, variando de erupções nodulares a inchaços difusos e a coloração varia de branca a rósea, podendo ocorrer áreas de hemorragia,

Quanto à ulceração, $51,8 \%$ (44/85) dos mastocitomas não apresentaram tal característica, enquanto que $29,4 \%$ (25/85) eram ulcerados e $8,2 \%$ (7/85) dos cães possuíam mais de um nódulo, apresentando tumores de ambos aspectos e nove $(10,6 \%)$ não possuíam informação.

Analisou-se tamanho e número de nódulos de mastocitoma e sua relação com grau histológico. No presente estudo, tumores não ulcerados possuem graduação mais baixa (I e II) (Tabela 2) e tumores ulcerados eram de maior grau, assim como relatado por Kiupel (2016) que verificaram que tumores ulcerados e pruriginosos como mais malignos.

Entre os 85 cães diagnosticados com mastocitomas no presente estudo, 62 animais $(72,9 \%)$ apresentaram apenas um nódulo (Tabela 3). Ao relacionar o número de nódulos com o grau histológico, foi possível observar que animais que apresentaram mais de 3 nódulos tiveram um maior percentual de mastocitomas grau II e III (73,9\%). Blackwood et al. (2012) descrevem a presença de nódulos satélites como um sinal clínico sugestivo de comportamento agressivo. 
TABELA 2 - Frequência de grau histológico de acordo com ulceração do nódulo de mastocitoma de cães atendidos no Hospital Veterinário da Universidade Federal de Uberlândia.

\begin{tabular}{llll|ll|l}
\hline & \multicolumn{3}{c|}{ Patnaik } & \multicolumn{4}{c}{ Kiupel } \\
\hline Grau Histológico & I & II & III & \multicolumn{2}{|c}{ Baixo } & Alto \\
\hline Ulceração & 3 & 14 & 8 & 13 & 12 \\
Sim & 14 & 26 & 4 & 30 & 13 \\
Não & 2 & 7 & - & 9 & - \\
NI & & & & & &
\end{tabular}

TABELA 3 - Frequência de grau histológico de acordo com tamanho, localização e número de nódulos de mastocitoma de cães atendidos no Hospital Veterinário da Universidade Federal de Uberlândia.

\begin{tabular}{lccc|cc}
\hline & \multicolumn{3}{c|}{ Patnaik } & \multicolumn{3}{c}{ Kiupel } \\
\hline Grau Histológico & I & II & III & Baixo & Alto \\
\hline No nódulos & & & & & \\
1 & 15 & 36 & 11 & 42 & 20 \\
2 & 5 & 7 & - & 9 & 3 \\
$>2$ & 1 & 7 & 3 & 6 & 5 \\
\hline Tamanho & & & & & \\
\hline T1 $(<5 \mathrm{~cm})$ & 10 & 27 & 6 & 29 & 14 \\
T2 $(5$ a $10 \mathrm{~cm})$ & 2 & 5 & 3 & 7 & 3 \\
T3 $(>10 \mathrm{~cm})$ & - & 4 & 1 & 1 & 4 \\
Múltiplos & 4 & 5 & 2 & 8 & 3 \\
NI & 5 & 9 & 2 & 12 & 4 \\
\hline Localização & & & & & \\
$\quad$ Cabeça & 1 & 8 & 1 & 5 & \\
Tronco & 6 & 17 & 6 & 20 & 9 \\
Membros & 5 & 9 & - & 12 & 2 \\
Inguinal & 1 & 12 & 2 & 7 & 8 \\
Múltiplos & 2 & 5 & 3 & 6 & 4 \\
NI & 6 & 1 & - & 7 & - \\
\hline Idade & & & & & \\
\hline 0-5 anos & 3 & 7 & - & 9 & 1 \\
$5-10$ anos & 9 & 19 & 7 & 25 & 10 \\
10-15 anos & 6 & 16 & 6 & 16 & 12 \\
NI & 3 & 8 & 1 & 6 & 6 \\
\hline
\end{tabular}

O tamanho dos nódulos variou de $0,5 \mathrm{~cm}$ a $25 \mathrm{~cm}$, em que a maioria $(50,6 \%)$ era menor que $5 \mathrm{~cm}$ (Tabela 3). Stefanello et al. (2015) relataram tamanhos semelhantes, com tumores entre 0,4 e $20 \mathrm{~cm}$, com mediana de $3 \mathrm{~cm}$. A maior frequência de nódulos pequenos pode estar relacionada aos cuidados que os 
proprietários tem dispensado aos seus cães e maior busca por auxílio veterinário ainda no início do crescimento tumoral.

Quanto à localização dos tumores nos cães estudados, 16,5\% (14/85) possuíam nódulos múltiplos e $7 / 85(8,2 \%)$ dos cães não possuíam informações sobre a localização dos tumores. O tronco foi a localização mais frequente $(29 / 85$ $34,1 \%$ ), seguido pela região inguinal (15/85 - 17,6\%) (Tabela 3). Costa et al. (2017) descreveram a genitália como a região mais acometida por mastocitoma $(28,15 \%)$, enquanto Braz et al. (2017) relataram a região do tronco como a mais frequente $(46,7 \%)$ e a cabeça a menos acometida (10\%).

Quanto à graduação, a maioria dos mastocitomas foram classificados como grau II (58,06\%) (Tabela 3). Silva et al. (2014) também relataram que os tumores de grau II foram os mais diagnosticados, seguidos pelos de grau I e, por último, os de grau III.

Segundo o método de Kiupel et al. (2011) a maioria dos mastocitomas foram graduados como de baixo grau 65,9\% (56/85) (Figura 1) e 31,8\% (27/85) alto grau. Resultado semelhante foi observado por Sabattini et al. (2015), com 65\% das neoplasias de baixo grau e 35\% classificadas como alto grau. Estes autores relataram ainda que todos os mastocitomas classificados anteriormente como grau I eram de baixo grau no sistema Kiupel e todos os graus III eram de alto grau.

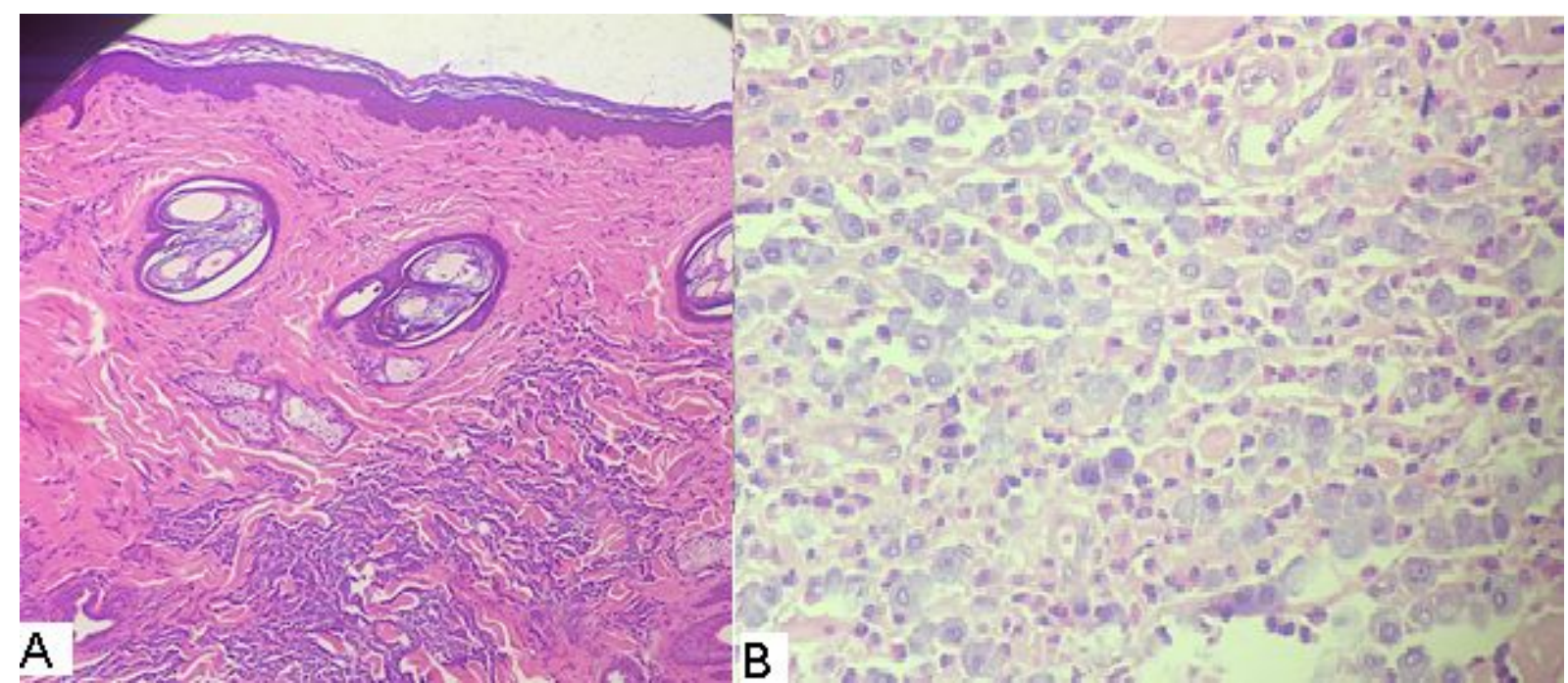

FIGURA 1 - Fotomicrografia de fragmento de pele. Mastocitoma cutâneo canino. A) Notar células redondas infiltrando na derme superficial, HE, $40 \mathrm{X}$. B: Observar células redondas, citoplasma amplo, presença de grânulos no citoplasma. De entremeio, nota-se eosinófilos.

Dentre os 40 casos graduados como grau II, após avaliação com coloração especial de AT, 27,5\% foram reclassificados como grau I (11/40). A utilização da coloração de AT em casos de mastocitoma grau II pode evitar que cães recebam tratamento mais agressivo, com margens cirúrgicas maiores e utilização de quimioterápicos e, em casos extremos, eutanásia, uma vez que o tratamento dos mastocitomas é baseado em achados clínicos e na classificação histológica (BLACKWOOD et al., 2012).

Quatro entre os 40 animais com grau II (10\%) foram reclassificados como grau III. Tumores classificados com um grau menor que o real, podem receber menor atenção do clínico e, consequentemente, apresentarem uma sobrevida 
menor. Além disto, a classificação errônea pode levar a um viés na interpretação de dados epidemiológicos.

Além de guiar o tratamento clínico, a graduação também é utilizada para predizer o prognóstico. Cerca de $55 \%$ dos animais com tumores de grau II sobrevivem até 3 anos após o diagnóstico e nos animais com grau III apenas 10 a $15 \%$ dos animais (PATNAIK et al. 1984).

\section{CONCLUSÃO}

Cães mais velhos apresentam mastocitomas de maior grau e o grau pode interferir no aspecto macroscópico, com mastocitomas grau II e II sendo mais frequentemente ulcerados. Atenção especial deve ser dispensada a nódulos no tronco e região inguinal, localizações comuns de mastocitomas.

A coloração de azul de toluidina pode ser utilizada como auxiliar para melhor avaliação de mastocitomas grau II, contribuindo para que a adoção de tratamento adequado. Com sua utilização e reclassificação dos tumores grau II pode se evitar medidas curativas muito agressivas em casos de mastocitomas que na realidade eram grau I e, por outro lado, tratamento pouco efetivo em casos de mastocitoma que na realidade eram grau III.

\section{REFERÊNCIAS}

BASTOS, R. S. C., DE FARIAS, K. M., LOPES, C. E. B., PACHECO, A. C. L., DE ARAÚJO VIANA, D. Estudo retrospectivo de neoplasias cutâneas em cães da região metropolitana de Fortaleza. Revista Brasileira de Higiene e Sanidade Animal, v. 11, n. 1, p. 39-53, 2017. Disponível em: <http://www.higieneanimal.ufc.br/seer/index.php/higieneanimal/article/view/375/1973

BLACKWOOD, L. et al. European consensus document on mast cell tumours in dogs and cats. Veterinary and Comparative Oncology, v. 10, n. 3, p. e1-e29, 2012. Disponível em: < https://doi.org/10.1111/j.1476-5829.2012.00341.x>

BRACARENSE, A. P. F. R. L.; PREUS, E.; MARCASSO, R. A.; REIS, A. C. F. Mastocitoma em cães - estudo retrospectivo de aspectos epidemiológicos e de sobrevida. Clínica Veterinária, v. 12, n. 98, p. 84-94, 2012. Disponível: < http://www.redalyc.org/html/4457/445744091016/>

BRAZ, P. H., HANIU, A. E. C. J., DE SOUZA, A. I., \& BRUM, K. B. Epidemiologia do mastocitoma em cães em uma região do Mato Grosso do Sul. PUBVET, v. 11, p. 0947-1073, 2017. Disponível em: < http://www.pubvet.com.br/artigo/4106/epidemiologia-do-mastocitoma-em-catildeesem-uma-regiatildeo-do-mato-grosso-do-sul>

CONCEIÇÃO, L. G., LOURES, F.H. Sistema tegumentar. In: SANTOS, R. L., ALESSI, A. C. Patologia Veterinária. 2. ed. Rio de Janeiro: Roca, p. 445-446. 2017.

COSTA, M. C., SILVA, A. L. D. A., MOREIRA, T. A., GUNDIM, L. F., MEDEIROS$\mathrm{RONCHI}, \mathrm{A}$. A. Prevalence and epidemiological and histopathological features of canine cutaneous mast cell tumours in Uberlândia, Brazil. Acta Veterinaria Brno, v. 
86, n. 2, p. 189-193, 2017. Disponível em: <https://doi.org/10.2754/avb201786020189>

CULLING, C. F., REID, P. E., DUNN, W. L. A new histochemical method for the identification and visualization of both side chain acylated and nonacylated sialic acids. Journal of Histochemistry \& Cytochemistry, v. 24, n. 12, p. 1225-1230, 1976. Disponível em: < https://doi.org/10.1111/j.1476-5829.2012.00341.x>

DE CARVAlHO, A. P. M., CARVALHO, E. C., DE NARDI, A. B., SILVEIRA, L. S. Comparação de duas classificações histopatológicas com o padrão de imunomarcação para KIT, a avaliação da proliferação celular e com a presença de mutações no c-KIT de mastocitomas cutâneos caninos. Pesquisa Veterinária Brasileira, v. 37, n. 4, p. 359-367, 2018. Disponível em: <https://doi.org/10.1590/s0100-736x2017000400010>

DE CARVAlHO, A. P. M., NOGUEIRA, G. M., LEANDRO, H. J., MEDINA, R. M., DE CARVALHO, E. C. Q., DE NARDI, A. B., DA SILVEIRA, L. S. Estudo retrospectivo do mastocitoma cutâneo canino utilizando duas classificações histopatológicas. Brazilian Journal of Veterinary Medicine, v. 39, n. 3, p. 170-175, 2017. Disponível em: < https://doi.org/10.29374/2527-2179.bjvm027316>

FERNANDES, C. C., MEDEIROS, A. A., MAGALHÃES, G. M., SZABÓ, M. P. J., DE QUEIROZ, R. P., DA SILVA, M. V. A., SOARES, N. P. Frequência de neoplasias cutâneas em cães atendidos no hospital veterinário da Universidade Federal de Uberlândia durante os anos 2000 a 2010. Bioscience Journal, v. 31, n. 2, 2015. Disponível em: < http://dx.doi.org/10.14393/BJ-v31n2a2015-22371>

FURLANI, J. M. et al. Mastocitoma Canino: Estudo Retrospectivo. Ciência Animal Brasileira, v. 9, n. 1, p. 242-250, 2008. Disponível em: < https://www.researchgate.net/profile/Felipe_Vicenti/publication/277770560_MASTOC ITOMA_CANINO_ESTUDO_RETROSPECTIVO/links/55bfa4b408ae9289a09b5df8.p $\mathrm{df}>$

INOUE, M., HASEGAWA, A., HOSOI, Y., \& SUGIURA, K. A current life table and causes of death for insured dogs in Japan. Preventive veterinary medicine, v. 120, n. $2, \quad$ p. 210-218, 2015. Disponível em: < https://doi.org/10.1016/j.prevetmed.2015.03.018>

KIUPEL, M., et al. Proposal of a 2-tier histologic grading system for canine cutaneous mast cell tumors to more accurately predict biological behavior. Veterinary pathology, v. 48, n. 1, p. 147-155, 2011. Disponível em:

<https://doi.org/10.1177/0300985810386469>

KIUPEL, M. Mast cell tumors. In: MEUTEN, Donald J. (Ed.). Tumors in domestic animals. 2. ed. Ames: John Wiley \& Sons, Inc, p. 176-200. 2016

MAGAlHÃES, A. M., RAMAdinhA, R. R., BARROS, C. S., PEIXOTO, P. V. Estudo comparativo entre citopatologia e histopatologia no diagnóstico de neoplasias 
caninas. Pesquisa Veterinária Brasileira, v. 21, n. 1, p. 23-32, 2001. Disponível em: < http://www.scielo.br/pdf/\%0D/pvb/v21n1/a06v21n1.pdf>

OWEN, L N,; Classification of Tumors in Domestic Animal, WGO. 1980

PATNAIK, A. K.; EHLER, W. J.; MACEWEN, E. G. Canine cutaneous mast cell tumor: morphologic grading and survival time in 83 dogs. Veterinary pathology, $v$. 21, n. 5, p. 469-474, 1984. Disponível em: <Disponível em: <https://doi.org/10.1177/030098588402100503>

SABATTINI, S., SCARPA, F., BERLATO, D., \& BETTINI, G. Histologic grading of canine mast cell tumor: is 2 better than 3 ?. Veterinary pathology, v. 52 , n. 1, p. 70 73, 2015. Disponível em: <https://doi.org/10.1177/0300985814521638>

SHOOP, S. J. et al. Prevalence and risk factors for mast cell tumours in dogs in England. Canine genetics and epidemiology, v. 2, n. 1, p. 1, 2015.Disponível em: < https://doi.org/10.1186/2052-6687-2-1>

SILVA, A. L. D. A., DE QUERIOZ, R. P., SZABÓ, M. P. J., MEDEIROS, A. A. Grau de malignidade do mastocitoma cutâneo canino quanto a localização segundo as classificações de Patnaik et al.(1984) e Kiupel et al.(2011). Revista Brasileira de Ciência Veterinária, v. 21, n. 3, 2014. Disponível em: <https://doi.org/10.22409/rbcv.v21i3.665>

STEFANELLO, D.et al. Comparison of 2-and 3-category histologic grading systems for predicting the presence of metastasis at the time of initial evaluation in dogs with cutaneous mast cell tumors: 386 cases (2009-2014). Journal of the American Veterinary Medical Association, v. 246, n. 7, p. 765-769, 2015. Disponível em: < https://doi.org/10.2460/javma.246.7.765> 